\title{
Using tool wear to increase process stability when milling Al7075 and AISI 4140+QT
}

\author{
Berend Denkena ${ }^{1} \cdot$ Alexander Krödel $^{1} \cdot$ Andreas Relard $^{1}[$
}

Received: 21 January 2021 / Accepted: 7 May 2021 / Published online: 13 May 2021

(c) The Author(s) 2021

\begin{abstract}
One of the main limits of productivity during cutting processes is the occurrence of regenerative chatter. Due to these self-excited vibrations, the load capacity of the machine components, the tool as well as the machine performance cannot be fully utilized. There are several methods to stabilize the milling process. One is the use of increased process damping, which results from the contact of the tool's flank face and the workpiece. The flank wear land naturally increases the contact between tool and workpiece. However, this effect has not been used to increase productivity in milling processes. This paper investigates with experiments and numerical simulations how tool wear affects process stability in milling of aluminum and steel. Therefore slot milling and side milling tests were carried out with tools of various states of flank wear. It could be shown that increasing flank wear allows to raise the depth of cut $\mathrm{a}_{\mathrm{p}}$ up to $300 \%$ in machining aluminum and perform the machining process with a higher productivity.
\end{abstract}

Keywords Wear $\cdot$ Milling $\cdot$ Productivity $\cdot$ Stability $\cdot$ Chatter

\section{Introduction}

There is a trend in the machine tool industry to increase spindle power and torque to meet the demand of higher metal removal rates and maximize the productivity of milling processes [1]. In most cases an increase of the process parameters (depth of cut $a_{p}$, width of cut $a_{e}$ ) is not limited by the performance of the machine tool, but by selfexcited vibrations (chatter) above a limiting depth of cut $\mathrm{a}_{\mathrm{p}, \lim }[2]$. Decisive for these vibrations is the regenerative effect. This effect describes the occurrence of chatter due to the dynamic compliance of the milling system. The additional high loads caused by these vibrations result in significant lifetime reductions for different components of the machine tool including the cutting tool itself and also damage the workpiece surface [3]. As a result, machines are operated below their theoretical capacity limit in order to avoid chatter vibrations. Various techniques to suppress chatter in metal cutting have been investigated over the last 60 years [1]. The easiest way to avoid chatter is the selection

Andreas Relard

relard@ifw.uni-hannover.de

1 Institute of Production Engineering and Machine Tools, An der Universität 2, 30823 Garbsen, Germany of suitable spindle speeds and depth of cuts, which lead to a stable zone in the stability lobe diagram. Besides active damping systems and damping tool holders, other techniques for stabilizing the milling processes are for example using special tool geometries that perturb the regenerative effect [4] or using specific cutting edge geometries [5]. Tunc and Budak investigated the influence of tool geometries and cutting conditions on process stability mainly by simulations. They stated that slow cutting speeds and larger cutting edge roundings result in higher process damping and thus higher process stability [6].

The process damping effect is based on the workpiece volume indented by the tool's flank face [7]. The damping force is caused by the indented workpiece volume from the tool's flank face and acts in opposite direction of the vibration and therefore reduces the amplitude of the vibration [1]. Previous investigations showed that a chamfer on the flank face, manufactured by grinding, increases process damping, which reduces the vibrations significantly $[1,8]$. Hence, the maximum depth of cut $\mathrm{a}_{\mathrm{p}, \mathrm{im}}$ could be increased significantly by a chamfer compared to conventional tools [8]. An ideal sharp cutting edge exhibits no contact between the flank face and the surface of the workpiece (Fig. 1a). With larger cutting edge roundings or a worn cutting edge, the contact surface and therefore the indented volume leads to an increase 

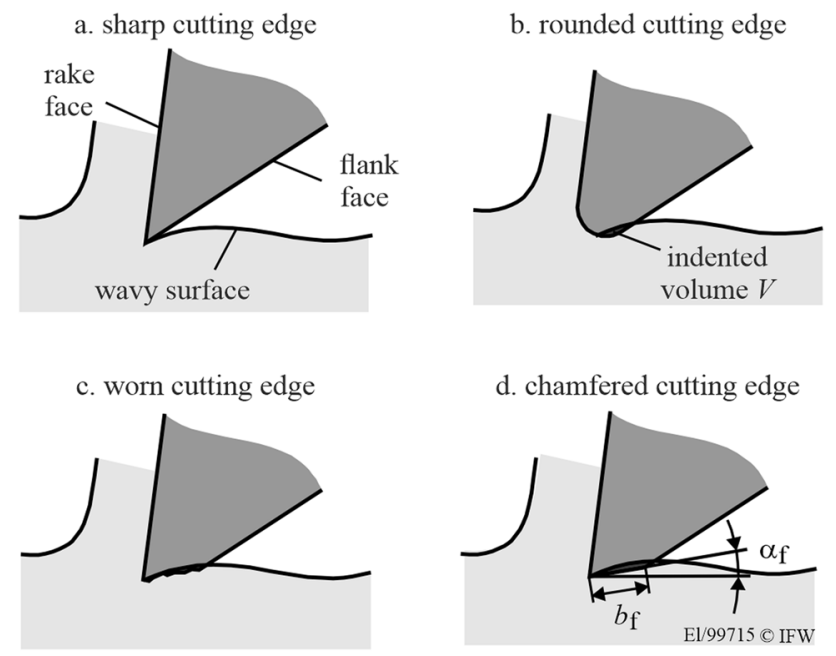

Fig. 1 Effect of different cutting edge geometries and worn cutting edge on intended volume and therefore on the process damping as in [6]

in damping force (Fig. 1b, c). This effect is used for rough milling tools by applying a chamfer to the tool to increase the possible indented volume $\mathrm{V}$ and optimize the process stability (Fig. 1d). However, the disadvantage is a reduced surface quality compared to unchamfered tools. Additionally, the production of the chamfer results in an increased effort during tool production especially in the quality assurance of small chamfers. The wear rate of flank wear is higher due to the smaller clearance angle of the chamfer although the cutting edge in total is more stable [9].

Several investigations showed that a similar effect to chamfering is caused by flank wear. Munoa et al. stated that worn tools can be used to avoid chatter as the process damping increases with flank wear [1]. Ahmadi and Ismail investigated simulations of stability lobe diagrams and compared the necessary resolution of discretization when using the semi-discretization method. For simulations with worn cutting edges a higher resolution is necessary to receive accurate results [10]. Altintas et al. showed the increase of process damping with tool wear [11]. Turning experiments with stainless steel SS304 were carried out with a new tool and one with $\mathrm{VB}_{\mathrm{B}}=0.08 \mathrm{~mm}$ flank wear. Several of the unstable cutting tests with the new tool were observed to become stable when tested with the worn tool. The stability investigations were carried out with one state of tool wear. Tyler and Schmitz explained the higher stability of worn tools with a higher process damping coefficient. In upmilling experiments and simulations they investigated an increase of this coefficient up to $31 \%$ for a cutting edge with flank wear of $\mathrm{VB}=200 \mu \mathrm{m}[12]$.

These investigations have in common that only one state of wear was used for the investigations and the stabilizing mechanisms of wear are simplified with an adjusted process

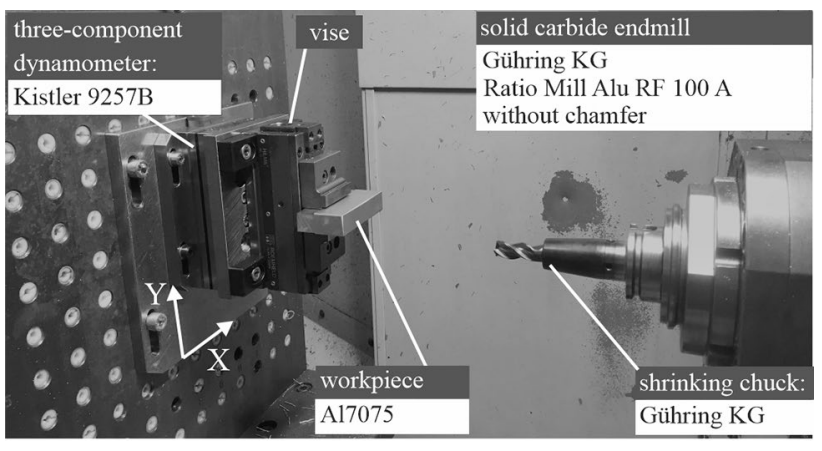

Fig. 2 Experimental setup for stability investigations of milling A17075

damping coefficient. The positive effect of tool wear with regard to increased process stability has not yet been systematically investigated with continuously increasing and different states of tool wear. This paper examines for the first time systematically the effect of various states of tool wear on the process stability in milling processes. Furthermore, a comparison is made between experimental stability diagrams and stability diagrams simulated with the semi-discretization method. A simulation which is in good agreement with the related experiment offers good possibilities to vary parameters and characterize the changes for stability without the need of more extensive experiments.

\section{Experimental}

\subsection{Stability investigations}

In order to investigate the potential of tool wear for increasing productivity, stability experiments in milling were conducted as well as a stability simulations based on the semidiscretization method. The experiments were carried out on a Heller MC16 4-axis machining center. A three-component dynamometer Kistler 9257B was used to measure the process forces. Two different processes were analyzed in terms of stability. One process was the milling of Al7075 with a tensile strength of $\mathrm{Rm}=525 \mathrm{~N} / \mathrm{mm}^{2}$. The other process was milling of quenched/tempered low-alloy steel AISI $4140+Q T$ with a tensile strength of $\mathrm{Rm}=886-935 \mathrm{~N} / \mathrm{mm}^{2}$.

\subsubsection{Milling of Al7075 with solid carbide end mills}

Figure 2 shows the experimental setup. Because of the low wear rate while machining Al7075 the depth of cut could be increased step by step every $100 \mathrm{~mm}$ and the tool wear between the steps could be neglected.

The modal input parameters mass, stiffness and damping, which are necessary for the stability calculations, were 
determined by the impulse hammer method. The resulting frequency response functions (FRF) are shown in Fig. 3. The main compliance of the workpiece in milling Al7075 is at $500 \mathrm{~Hz}$ for both $\mathrm{x}$ - and $\mathrm{y}$-direction. The compliance of the tool has two peaks, one at $1,625 \mathrm{~Hz}$ and one at $3,415 \mathrm{~Hz}$.

By comparing the amplitudes of the FRF's it can be seen that the workpiece is slightly more rigid with a compliance of $0.25 \mu \mathrm{m} / \mathrm{N}$ in $\mathrm{x}$-direction and $0.4 \mu \mathrm{m} / \mathrm{N}$ in $\mathrm{y}$-direction. The tool has a compliance of $0.6 \mu \mathrm{m} / \mathrm{N}$ in $\mathrm{x}$-direction and $0.4 \mu \mathrm{m} / \mathrm{N}$ in $\mathrm{y}$-direction (Fig. 3).

Aluminum was machined without coolant with uncoated, polished solid carbide end mills (Table 1).

To investigate the stability in milling A17075, slot milling was carried out with a constant depth of cut at each specimen. The depth of cut was increased in discrete steps until chatter was noticed in the force measurements of feed force, feed normal force and the machined surface quality (Fig. 4). The spindle speed was varied between $n=10,000-22,000$ $\mathrm{min}^{-1}$ in steps of $2000 \mathrm{~min}^{-1}$. The max. cutting speed is with $\mathrm{v}_{\mathrm{c}}=1.100 \mathrm{~m} / \mathrm{min}$ still below the limit of high speed cutting. The depth of cut was varied between $a_{p}=2-7 \mathrm{~mm}$ in steps of $1 \mathrm{~mm}$. To show differences between various wear conditions, new tools $(\mathrm{VB}=0 \mu \mathrm{m})$ as well as tools with defined width of flank wear $(\mathrm{VB}=15 \mu \mathrm{m}, \mathrm{VB}=30 \mu \mathrm{m}, \mathrm{VB}=90 \mu \mathrm{m})$

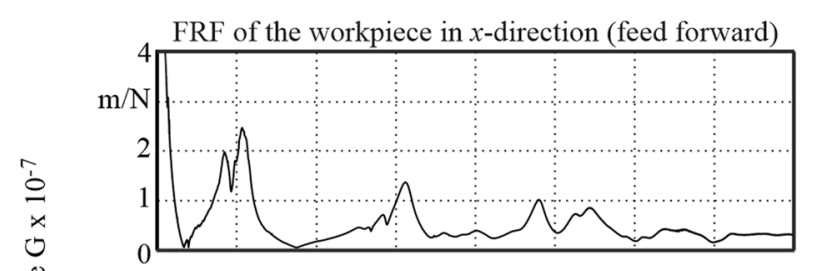

莺
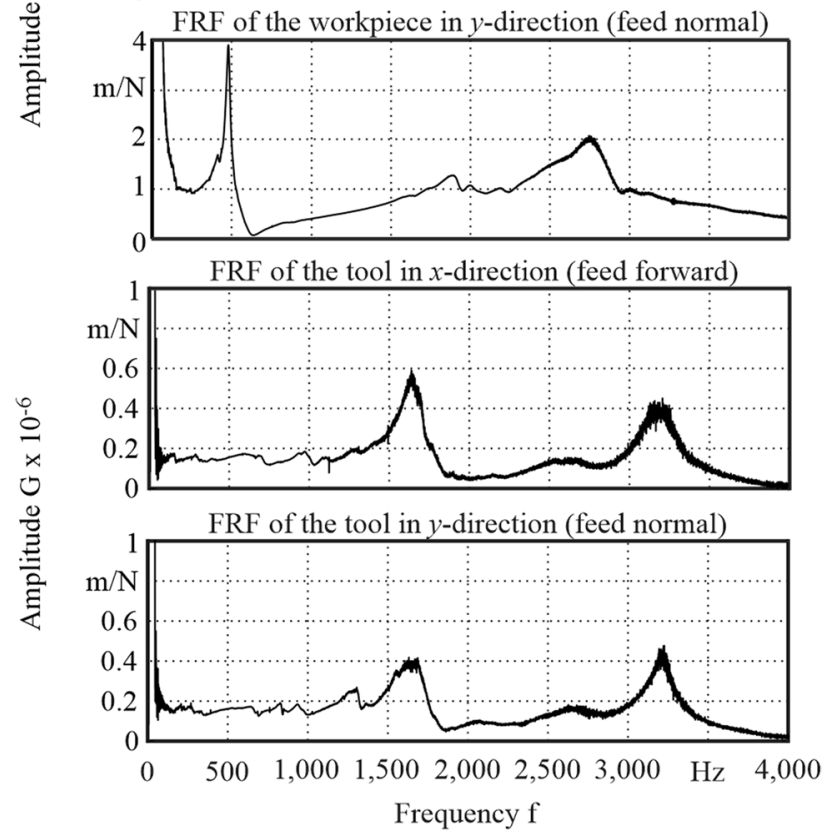

Fig. 3 FRF of workpiece and tool from milling process A17075
Table 1 Tool geometry of solid carbide end mill

\begin{tabular}{ll}
\hline Diameter $\mathrm{D}$ & $16 \mathrm{~mm}$ \\
Number of teeth $\mathrm{N}_{\mathrm{t}}$ & 3 \\
Corner radius $\mathrm{r} \varepsilon$ & $1 \mathrm{~mm}$ \\
Rake angle $\gamma$ & 10 \\
Clearance angle $\alpha$ & 10 \\
Helix angle $\delta$ & $39 ; 40 ; 41^{\circ}$ \\
Feed per tooth $\mathrm{f}_{\mathrm{z}}$ & $0.1 \mathrm{~mm}$ \\
\hline
\end{tabular}

were used. The flank wear was defined by using an optical topography measurement system based on focus variation Alicona Infinite Focus G5. Based on the force measurements and the machined surface quality, chatter vibrations and the maximum depth of cut can be determined. Figure 4 shows one example from the experiments with Al7075.

At the top of Fig. 4 the surface quality of the machined specimen is shown. For the unstable process chatter marks can be clearly detected. Additionally the force measurements in time and frequency domain are shown. When the process becomes unstable, the force amplitude increases significantly and chatter vibrations can be detected. The force measurements in frequency domain are described in a spectrogram, where the force frequency is plotted over time and the force amplitude is displayed by color. In this spectrogram the tooth engagement frequency and the natural frequencies of the tool can be differentiated from the chatter frequencies.
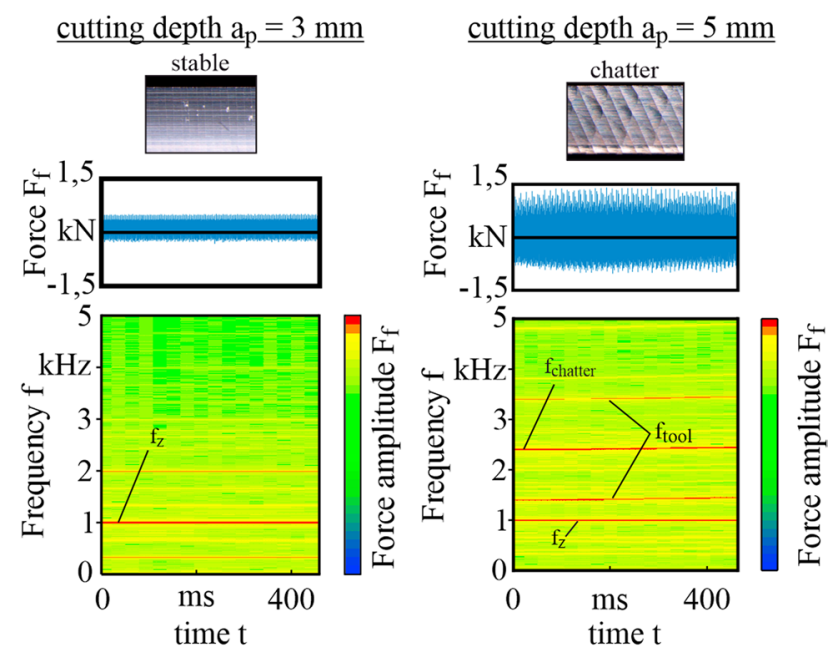

$$
\begin{array}{ll}
\hline \text { Tool } & \text { Process Parameters } \\
\text { Ratio Mill Alu RF 100 A } \mathrm{n}=20,000 \mathrm{~min}^{-1} \\
\\
\mathrm{a}_{\mathrm{p}}=\text { var.; } \mathrm{a}_{\mathrm{e}}=16 \mathrm{~mm} \\
\mathrm{f}_{\mathrm{Z}}=0.1 \mathrm{~mm}
\end{array}
$$

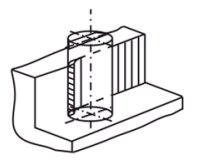

Fig. 4 Determination of chatter when machining A17075 


\subsubsection{Milling of AISI 4140+QT with a long cantilevered indexable insert mill}

Figure 5 shows the experimental setup. Because of the higher wear rate while machining AISI 4140+QT a different setup was used where special workpieces with $\mathrm{a}_{\mathrm{p}}$-ramps were machined. With these workpieces it was possible to investigate various depths of cut in one milling path and determine the maximum depth of cut.

The resulting frequency response functions (FRF) of the modal analysis for milling steel are shown in Fig. 6. The compliances in milling AISI 4140+QT are characterized by one main peak at $1000 \mathrm{~Hz}$ for the tool and the workpiece in $\mathrm{x}$ - and $\mathrm{y}$-direction (Fig. 6). For this setup the workpiece is more rigid with a compliance of $0.06 \mu \mathrm{m} / \mathrm{N}$ compared to the tool with a compliance of $4 \mu \mathrm{m} / \mathrm{N}$. This shows that the tool has the highest impact for the stability of the steel milling process. On the one hand it is because of the length of the tool. On the other hand the tool-body consisting of steel in contrast to cemented carbide for the monolithic tool also has an effect on rigidity.

Steel was machined without coolant with a long (188 $\mathrm{mm}$ ) cantilevered indexable insert milling cutter with coated $\left(\mathrm{Al}_{2} \mathrm{O}_{3}\right)$ solid carbide inserts (Table 2). The long milling cutter was used to investigate the potential of tool wear in compliant milling processes.

To investigate the stability in the milling AISI $4140+$ QT process, side milling was carried out due to the low stiffness of the long cantilevered end mill. The spindle speed was varied between $n=1,300-5,500 \mathrm{~min}^{-1}$ in steps of $700 \mathrm{~min}^{-1}$. Because of the low stiffness of the end mill a low width of cut $\mathrm{a}_{\mathrm{e}}=2 \mathrm{~mm}$ was chosen. Due to the faster wear during dry steel machining, the depth of cut was continuously varied by machining $\mathrm{a}_{\mathrm{p}}$-ramps with a gradient of $3 \mathrm{~mm}$ on $100 \mathrm{~mm}$ workpiece length. Special workpieces were prepared, with which the cutting depth varied from $a_{p}=0-6 \mathrm{~mm}$. The depth of cut, where chattering occurs was determined by force measurements and analysis of the machined surface (Fig. 7) analogous to Fig. 4. For this process, new inserts and inserts with defined flank wear

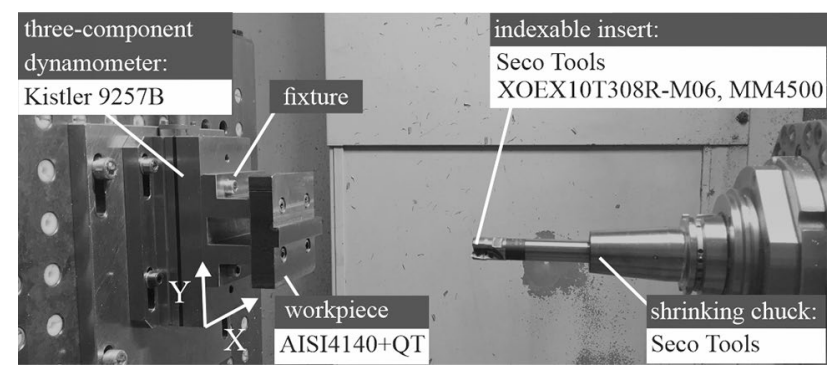

Fig. 5 Experimental setup for stability investigations of milling AISI 4140+QT

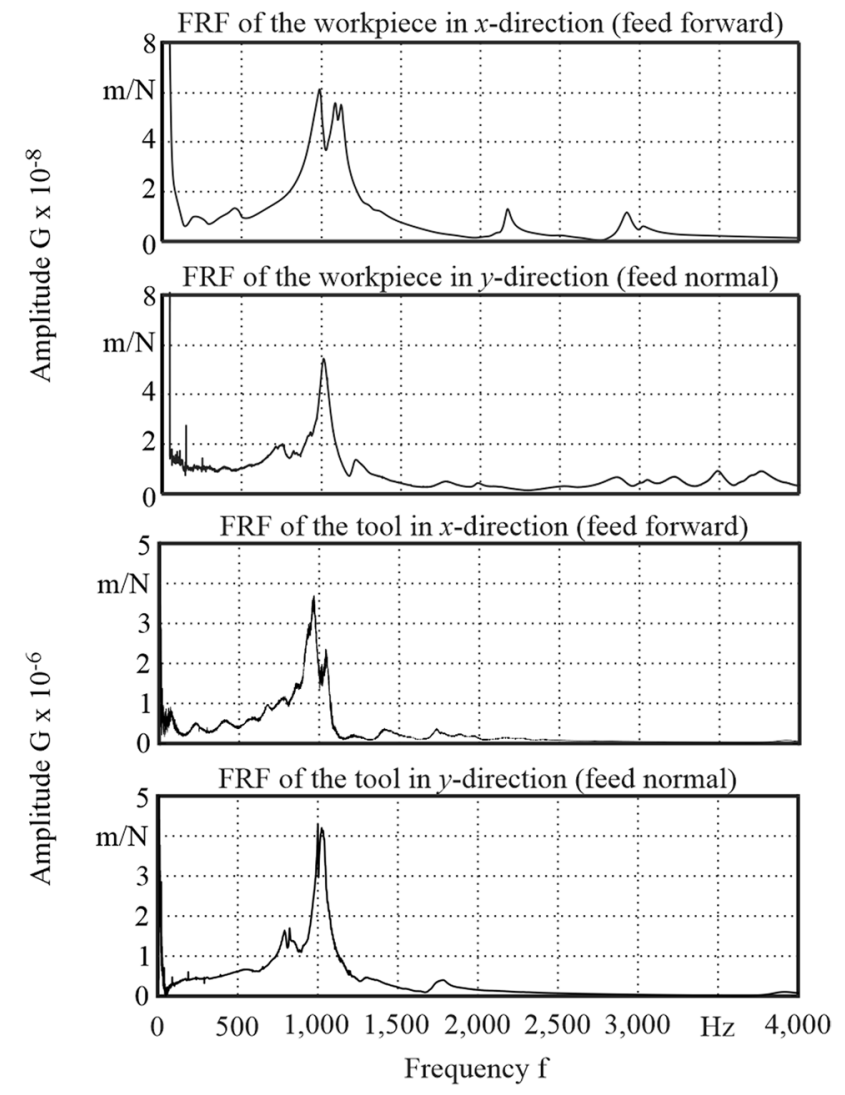

Fig. 6 FRF of workpiece and tool from milling process AISI 4140+QT

width $(\mathrm{VB}=10 \mu \mathrm{m}, \mathrm{VB}=30 \mu \mathrm{m}, \mathrm{VB}=50 \mu \mathrm{m})$ were used. The tests were repeated once.

\subsection{Tool wear}

Before the stability experiments with defined worn tools could be performed, it was necessary to analyze the wear behavior of the tools and its change over time. For this purpose, wear tests were carried out for the two different milling processes.

Table 2 Tool geometry of indexable insert milling cutter

\begin{tabular}{ll}
\hline Diameter $\mathrm{D}$ & $20 \mathrm{~mm}$ \\
Number of teeth $\mathrm{N}_{\mathrm{t}}$ & 2 \\
Corner radius $\mathrm{r}_{\varepsilon}$ & $0.8 \mathrm{~mm}$ \\
Rake angle $\gamma$ & 11 \\
Clearance angle $\alpha$ & 9 \\
Helix angle $\delta$ & 12 \\
Feed per tooth $\mathrm{f}_{\mathrm{z}}$ & $0.08 \mathrm{~mm}$ \\
\hline
\end{tabular}




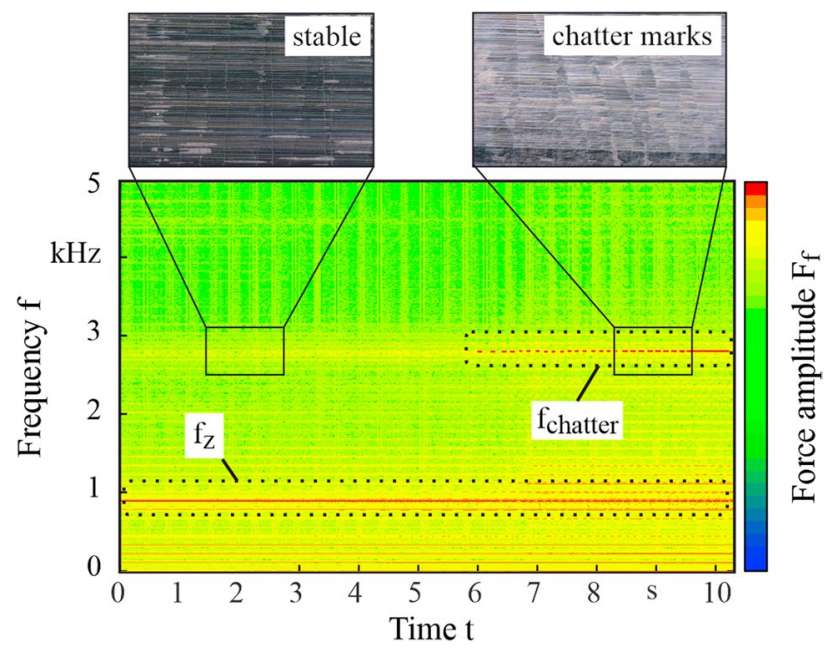

Fig. 7 Determination of chatter when machining AISI 4140+QT

\subsubsection{Milling of Al7075 with solid carbide end mills}

Due to the low wear when machining A17075, EN AC-43,000 was machined to achieve wear on the cutting edge. Because of the high proportion of silicon, the material is highly abrasive and wear occurs more quickly. Tests before showed a similar tool wear compared to milling Al7075 in the investigated range of cutting speed (Fig. 8).

Figure 9 shows the wear diagram of the aluminum milling process.

The process parameters for achieving defined worn tools were chosen in a range where even wear on the flank face occurred. This was mandatory for the stability investigations, because process damping is only caused by the contact of the flank face. For the same reason, crater wear or breakouts were not desired.

Based on the wear diagrams, three states of wear were selected for the stability investigations. The corresponding cutting edges of the tools are shown in Fig. 10. The wear that occurred on the tools was analyzed with a scanning electron microscope (SEM) Zeiss EVO 60 VP (Fig. 10, left) and an
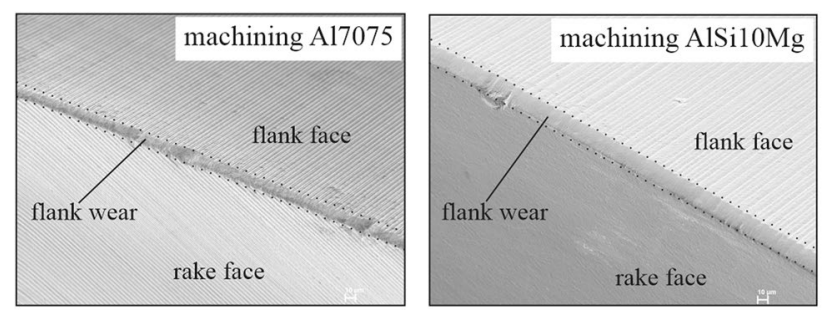

Fig. 8 Flank wear when machining A17075 and AlSi10Mg with solid carbide end mill $\left(n=10,000 \mathrm{~min}^{-1}, \mathrm{f}_{\mathrm{z}}=0.17 \mathrm{~mm}, \mathrm{a}_{\mathrm{p}}=5 \mathrm{~mm}, \mathrm{a}_{\mathrm{e}}=6.4\right.$ $\mathrm{mm}$, down milling)

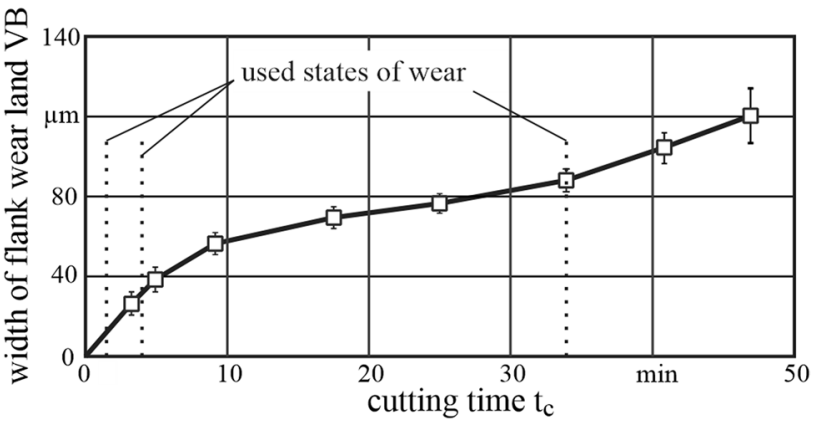

Fig. 9 Wear diagram for machining EN AC-43000 $\left(n=10,000 \mathrm{~min}^{-1}\right.$, $\mathrm{f}_{\mathrm{z}}=0.17 \mathrm{~mm}, \mathrm{a}_{\mathrm{p}}=5 \mathrm{~mm}, \mathrm{a}_{\mathrm{e}}=6.4 \mathrm{~mm}$, down milling)

optical topography measurement system based on focus variation Alicona Infinite Focus G5 (Fig. 10, right).

Figure 10 shows the three states of tool wear, which were later used for the stability investigations with Al7075. The cutting edge profile sections of the worn edges show changes of the tool's microgeometry. With increasing tool wear the clearance angle in the area of wear decreases and becomes negative near the cutting edge. The negative clearance angle of the flank face in the area of wear leads to a larger contact area of the tool and the workpiece and therefore to a higher indented volume of the flank face and workpiece. This results in a higher process damping. Because of bigger cutting edge radii also the ploughing increases which results in higher ploughing forces and puts additional loads to the cutting edge. The profile sections also show that with increasing wear the diameter of the tools decreases. Therefore, an increasing productivity caused by tool wear is only useful for rough machining, where small differences of tool diameters are acceptable.

\subsubsection{Milling of AISI 4140+QT with a long cantilevered indexable insert mill}

Analogous to the wear investigations of aluminum, the tool wear was also analyzed for milling of AISI 4140+QT. The results are shown in Fig. 11.

By using a short tool it was ensured that no chatter occurs and the uniform wear arises. The wear diagrams show the typical course with degressive wear in the beginning, constant wear in the middle and progressive wear at the end of the tool life.

Figure 12 shows the three states of tool wear, which were later used for the stability investigations with AISI $4140+$ QT. The width of flank wear is evenly distributed along the cutting edge. Crater wear occurred only on the rake face of the insert with the biggest width of flank wear with $\mathrm{VB}=50 \mu \mathrm{m}$ caused by the longer machining time. In this state of tool wear the coating was broken off the cemented carbide. 
Fig. 10 Wear of solid carbide end mills when milling EN AC-43000 $\left(\mathrm{n}=10,000 \mathrm{~min}^{-1}\right.$, $\mathrm{f}_{\mathrm{z}}=0.17 \mathrm{~mm}, \mathrm{a}_{\mathrm{p}}=5 \mathrm{~mm}$, $\left.\mathrm{a}_{\mathrm{e}}=6.4 \mathrm{~mm}\right)$
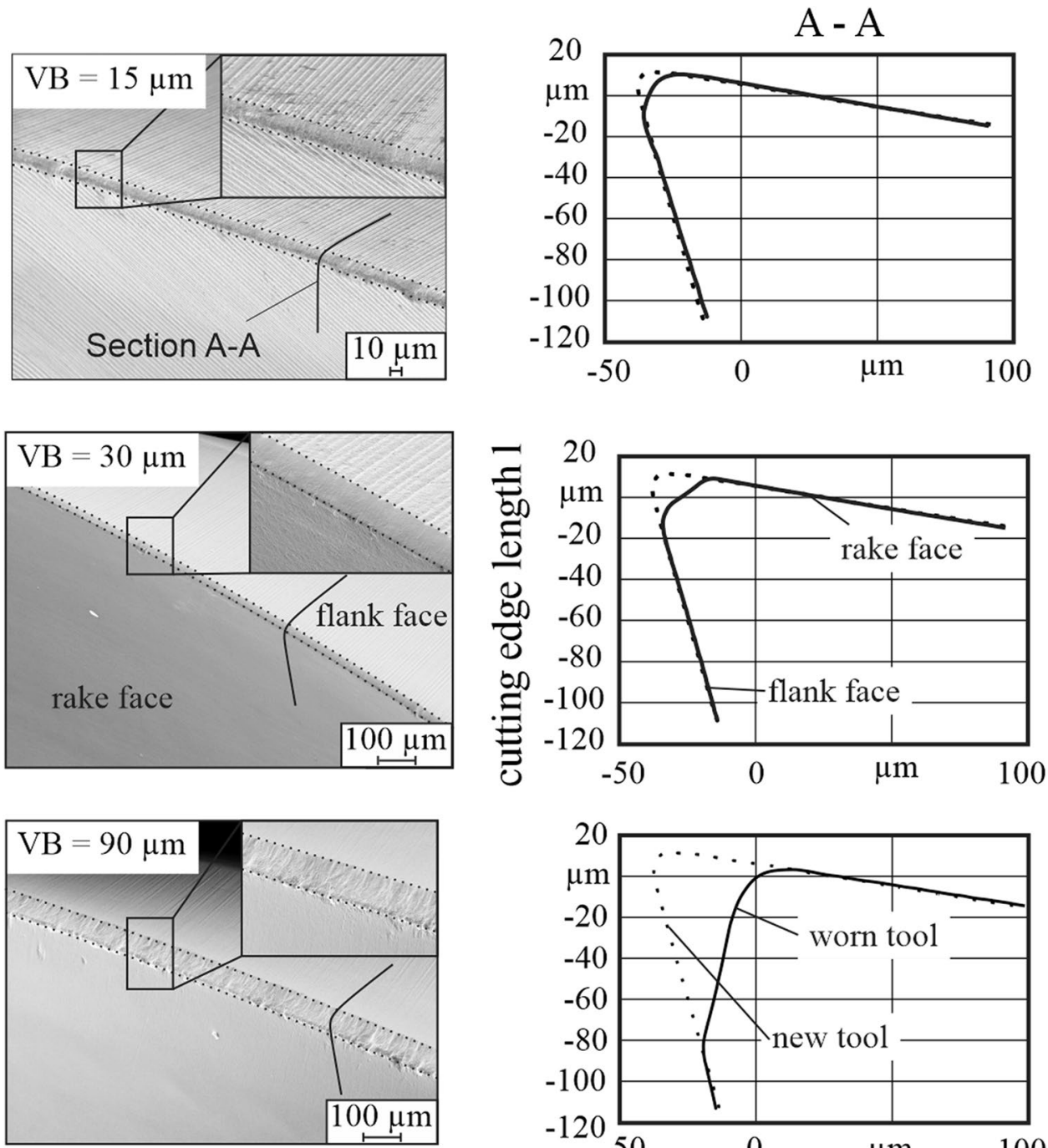

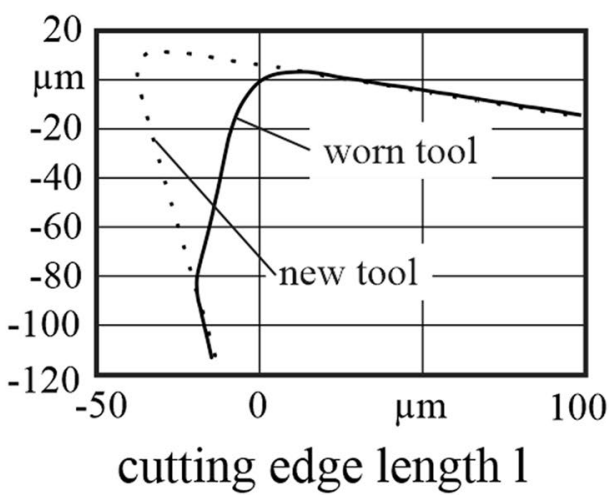

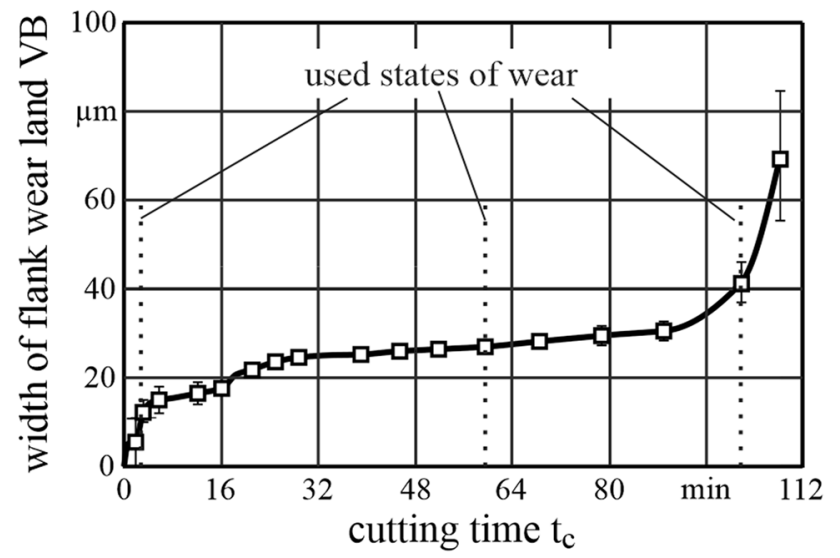

Fig. 11 Wear diagram for machining AISI 4140+QT with short, stiff tool $\left(n=2,000 \mathrm{~min}^{-1}, \mathrm{f}_{\mathrm{z}}=0,08 \mathrm{~mm}, \mathrm{a}_{\mathrm{p}}=2 \mathrm{~mm}, \mathrm{a}_{\mathrm{e}}=12 \mathrm{~mm}\right.$, down milling)

\section{Results of stability investigations}

\subsection{Milling of Al7075 with solid carbide end mills}

In order to quantify the effect of tool wear on process stability, stability diagrams for various states of tool wear (VB $=0-90 \mu \mathrm{m})$ were created experimentally. Figure 13 shows the results for machining Al7075.

For the new tool, a stability limit between 2 and 4 $\mathrm{mm}$ was detected. The absolute stability limit is $2 \mathrm{~mm}$. It describes the value of cutting depth $a_{p}$ that leads to stable milling processes across all spindle speeds. The tool with the smallest investigated width of flank wear $\mathrm{VB}=15$ $\mu \mathrm{m}$ results in higher process stability for spindle speeds $\mathrm{n}=12,000 \mathrm{~min}^{-1}$ and $\mathrm{n}=16,000 \mathrm{~min}^{-1}$. For these spindle speeds the maximum depth of cut increased by $1 \mathrm{~mm}$. The stability of the tool with flank wear $\mathrm{VB}=30 \mu \mathrm{m}$ changes 
Fig. 12 Wear of indexable inserts when milling AISI 4140+QT $\left(\mathrm{n}=2,000 \mathrm{~min}^{-1}\right.$, $\mathrm{f}_{\mathrm{z}}=0.08 \mathrm{~mm}, \mathrm{a}_{\mathrm{p}}=2 \mathrm{~mm}, \mathrm{a}_{\mathrm{e}}=12$ $\mathrm{mm}$, cutting time $\mathrm{t}_{\mathrm{c}}=3 / 47 / 102$ $\min$ )
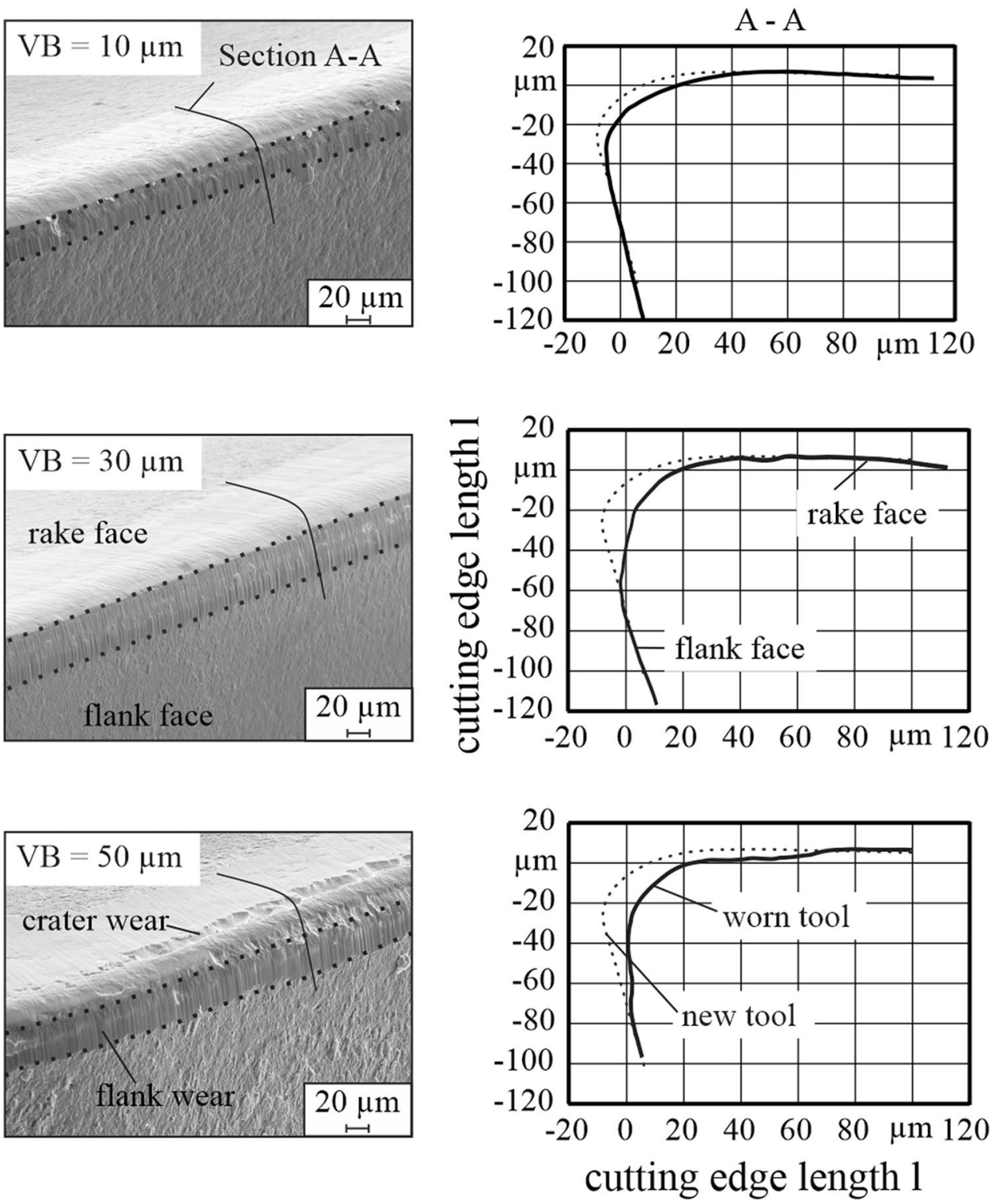

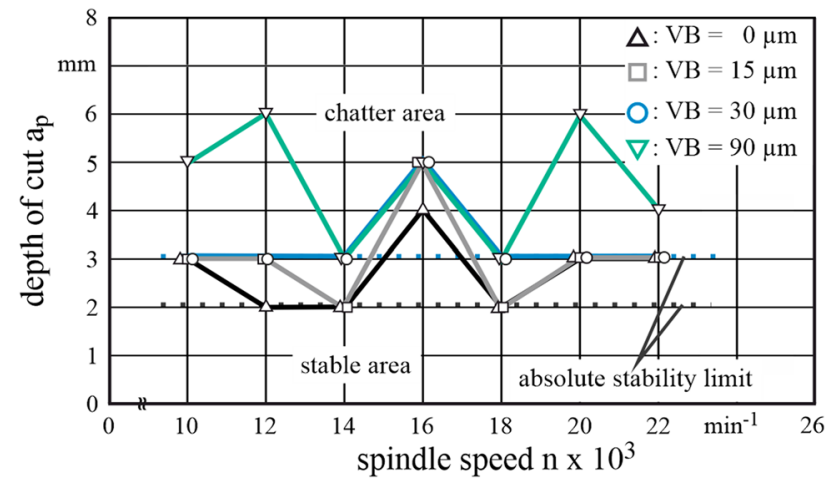

Fig. 13 Experimental stability diagrams of machining A17075 with various tool wear states $\left(f_{z}=0.1 \mathrm{~mm}, a_{e}=16 \mathrm{~mm}\right)$ for spindle speeds $n=14,000 \mathrm{~min}^{-1}$ and $\mathrm{n}=18,000 \mathrm{~min}^{-1}$ where the absolute stability limit for all spindle speeds increases by $1 \mathrm{~mm}$. With the largest width of flank wear $\mathrm{VB}=90 \mu \mathrm{m}$ the largest increase in stability can be achieved. Also the stability of the cutting edge increases due to increasing cutting edge radii. Bigger cutting edge roundings reduce the stress concentration in the tool tip and the cutting edge becomes more stable [5]. The higher process stability is particularly noticeable for $n=12,000$ $\min ^{-1}$ and $\mathrm{n}=20,000 \mathrm{~min}^{-1}$. Here, the cutting depth can be increased to $a_{p}=6 \mathrm{~mm}$ (from $a_{p}=2 \mathrm{~mm}$ and $a_{p}=3 \mathrm{~mm}$ ). This increase in stability is expected to result from the increased process damping, caused by greater contact of the flank face. With flank wear VB $=30 \mu \mathrm{m}$ the absolute stability limit increases from $\mathrm{a}_{\mathrm{p}, \lim }=2 \mathrm{~mm}$ to $\mathrm{a}_{\mathrm{p}, \mathrm{lim}}=3 \mathrm{~mm}$. 


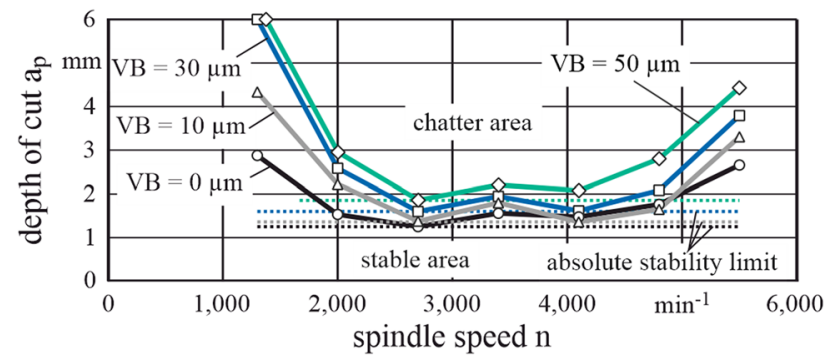

Fig. 14 Experimental stability diagrams of machining AISI $4140+Q T$ with various tool wear states $\left(\mathrm{f}_{\mathrm{z}}=0.08 \mathrm{~mm}, \mathrm{a}_{\mathrm{e}}=2 \mathrm{~mm}\right)$

\subsection{Milling of AISI 4140+QT with a long cantilevered indexable insert mill}

The stability diagrams of the long cantilevered indexable insert mill with $\mathrm{VB}=0-50 \mu \mathrm{m}$ in milling AISI 4140+QT are shown in Fig. 14. The discrete points for each maximum depth of cut were determined with the method shown in Fig. 7.

The stability diagrams show a steady increase of the absolute stability limit with increasing tool wear. The absolute stability limit of a new tool is at $\mathrm{a}_{\mathrm{p}, \mathrm{lim}}=1,25 \mathrm{~mm}$ and increases continuously to $a_{p, l i m}=1,6 \mathrm{~mm}$ with a width of flank wear of $\mathrm{VB}=50 \mu \mathrm{m}$. This results in an increase of process stability of $28 \%$. The state of tool wear with $\mathrm{VB}=50 \mu \mathrm{m}$ shows also crater wear, which can be one reason for the less increased stability compared to the other states of tool wear. The effect of higher process stability with worn cutting edges is bigger at exceptionally low spindle speeds $\left(\mathrm{n}=1,300 \mathrm{~min}^{-1}\right)$ from $2.8 \mathrm{~mm}$ to $6 \mathrm{~mm}$ and very high spindle speeds $\left(\mathrm{n}=5,500 \mathrm{~min}^{-1}\right)$ from 2.6 $\mathrm{mm}$ to $4.22 \mathrm{~mm}$. This can be attributed to the longer contact time between flank face and workpiece at low spindle speeds [3] and to high speed damping effects due to mode coupling as described in [13].

\subsection{Calculated stability charts}

Experimental stability investigations are very extensive and time consuming. Calculating the stability limits with simulations offers a possibility to predict the stability limit without the need of experiments on a machine tool. In order to calculate the process stability of the two machining processes, a simulation based on the semi-discretization derived in [8, 14] was used. The process damping force is calculated as described in $[8,15]$ :

$F_{\mathrm{r}, \mathrm{pd}}(t)=V(t) K_{\mathrm{pd}}$

$F_{\mathrm{t}, \mathrm{pd}}(t)=\mu V(t) K_{\mathrm{pd}}$

The process damping coefficient was set to the value $\mathrm{K}_{\mathrm{pd}}=50,000 \mathrm{~N} / \mathrm{mm}^{3}$ and added to the damping of the modes
Table 3 Specific force coefficients of machining Al7075 with solid carbide end mills

Table 4 Specific force coefficients of machining AISI 4140+QT with indexable insert mill

\begin{tabular}{lc}
\hline $\mathrm{K}_{\mathrm{tc}}$ & $1310.2 \mathrm{~N} / \mathrm{mm}^{2}$ \\
$\mathrm{~K}_{\mathrm{rc}}$ & $893.4 \mathrm{~N} / \mathrm{mm}^{2}$ \\
$\mathrm{~K}_{\mathrm{ac}}$ & $148.76 \mathrm{~N} / \mathrm{mm}^{2}$ \\
$\mathrm{~K}_{\mathrm{te}}$ & $12.37 \mathrm{~N} / \mathrm{mm}^{2}$ \\
$\mathrm{~K}_{\mathrm{re}}$ & $46.8 \mathrm{~N} / \mathrm{mm}$ \\
$\mathrm{K}_{\mathrm{ae}}$ & $2.4 \mathrm{~N} / \mathrm{mm}$ \\
\hline
\end{tabular}

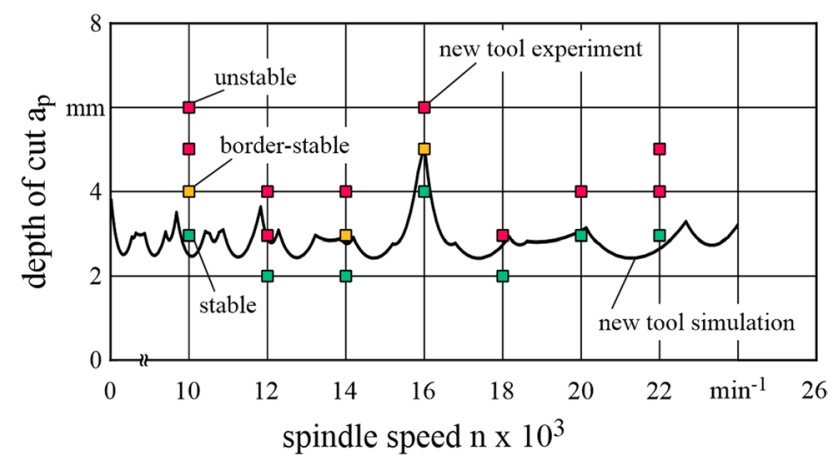

Fig. 15 Experimental and simulated stability diagram of machining Al7075 with new solid carbide end mills

analyzed with the modal analysis as stated in [13]. For the calculation of the stability charts, modal parameters and force coefficients were required beforehand. Stable milling tests with various feed rates were carried out to determine the force coefficients described in [15] and used in the simulation (Tables 3 and 4).

Additionally, the geometry of the tool was implemented in the simulation. The micro geometry of the tool wear was approximated according to the profile sections from Fig. 10 and Fig. 12.

\subsubsection{Milling of Al7075 with solid carbide end mills}

The experimental and simulated stability lobes in milling A17075 are presented in Fig. 15. The black, continuous line represents the stability limit from the simulation. Above the line, all parameters are unstable, parameters below the line are stable. The colored squares represent the experimental data. The simulation is in good agreement with the experimental results. 
Especially the peak at spindle speed $n=16,000 \mathrm{~min}^{-1}$ matches the simulation well. The peak is the result of the highest rigidity of the setup for the tooth engagement frequency of $800 \mathrm{~Hz}$. The knowledge about this peak is important to choose machining parameters for the highest productivity without stability issues. The result for machining Al7075 with solid carbide end mills with a width of flank wear of $\mathrm{VB}=90 \mu \mathrm{m}$ is shown in Fig. 16. The experiments are in good agreement in a wide range of spindle speeds. Only one stability lobe at spindle speed $n=20,000 \mathrm{~min}^{-1}$ cannot be displayed in the simulation. As assumed in [14], where similar effects occurred, this can be attributed to plastic deformation and thermal effects. These effects cannot be considered in this simulation.

\subsubsection{Milling of AISI 4140+QT with a long cantilevered indexable insert mill}

The experimental and simulated stability lobes for machining AISI4140+QT with the long cantilevered indexable insert mill without wear are presented in Fig. 17. Overall, there is an overestimation of the experimental stability of the milling process. This is due to the milling strategy of machining $\mathrm{a}_{\mathrm{p}}$-ramps. When reaching the critical depth of cut $a_{p, l i m}$, the system needs a certain time to oscillate, so chatter vibrations can be detected. In this delay time the depth of cut increases and instability is detected at a higher depth of cut. To prove this effect a brief trial with constant $a_{p}$ was conducted (Fig. 17, green line).

The experimental results in milling with constant $a_{p}$ are at the upper stability limit of the simulation and therefore in better agreement with the simulation. This shows that for a accurate determination of the process stability it is better to use a setup for milling with a constant $a_{p}$. In this case it was decided to keep the setup with $\mathrm{a}_{\mathrm{p}}$-ramps because of the fast wear occurrence in milling AISI 4140+QT. The comparison of experimental and simulated stability investigations for

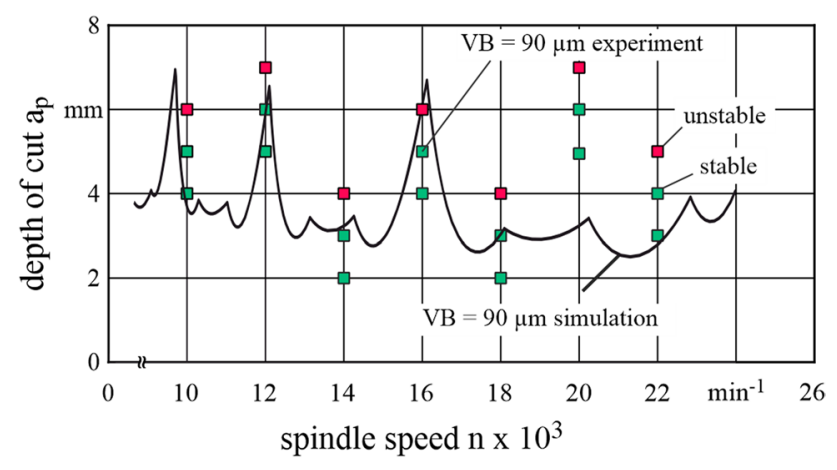

Fig. 16 Experimental and simulated stability diagram of machining A17075 with worn solid carbide end mills $(\mathrm{VB}=90 \mu \mathrm{m})$ the tool with indexable inserts with a width of flank wear of $\mathrm{VB}=50 \mu \mathrm{m}$ is shown in Fig. 18.

The results of the worn tool show the same effect of overestimating the stability when machining $a_{p}$-ramps over a wide range of spindle speeds. The main deviations between experiment and simulation can be seen for low spindle speeds from $n=1,300 \mathrm{~min}^{-1}$ to $\mathrm{n}=2,000 \mathrm{~min}^{-1}$ and for high spindle speeds above $\mathrm{n}=4,000 \mathrm{~min}^{-1}$. For low spindle speeds the simulation calculates a higher stability compared to the experiment, which means the simulation overestimates the process damping effect of tool wear. For high spindle speeds the deviations between experiment and simulation become larger. This can be explained with the high speed damping effect which cannot be considered in the simulation. The high speed process damping effect results from mode interactions of low frequency modes with the high frequency modes [13]. Despite these deviations, a good estimation of the stability for a tool with defined wear can be made in that range of spindle speeds that is of industrial relevance.

\subsection{Wear stability map}

To evaluate the potential of higher process stability with increasing tool wear, a method is introduced, which shows the spindle speed, width of flank wear and the maximum depth of cut in one map. With this map, it is possible to

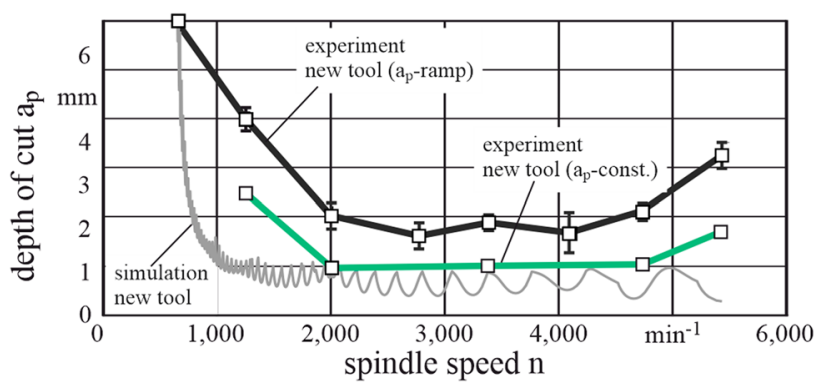

Fig. 17 Experimental and simulated stability diagram of machining AISI 4140+QT with a long cantilevered indexable insert mill (new inserts)

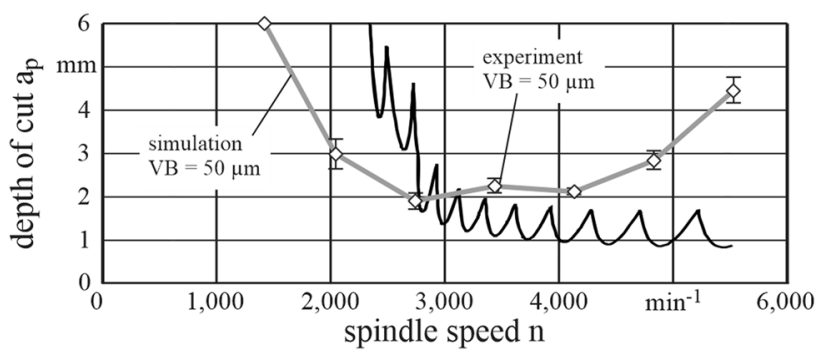

Fig. 18 Experimental and simulated stability diagram of machining AISI 4140+QT with a long cantilevered indexable insert mill $(\mathrm{VB}=50 \mu \mathrm{m})$ 
quantify changes in terms of stability with tool wear and to select suitable process parameters for increasing productivity.

\subsubsection{Milling of Al7075 with solid carbide end mills}

For the machining process of Al7075 it can be seen that there is a potential in an early state of tool life at spindle speeds of $n=16,000 \mathrm{~min}^{-1}$ (Fig. 19a) because of small width of flank wear to increase productivity. At this spindle speed, the cutting depth can be increased by $25 \%$ with a flank wear of $\mathrm{VB}=15 \mu \mathrm{m}$. In comparison, at $\mathrm{n}=12,000$ $\min ^{-1}$ and $\mathrm{n}=20,000 \mathrm{~min}^{-1}$ this potential only occurs upon a flank wear of $\mathrm{VB}=60 \mu \mathrm{m}$. Accordingly, despite the lower spindle speed, higher productivity can be achieved earlier than at $\mathrm{n}=20,000 \mathrm{~min}^{-1}$. Considering the slow increase in wear during aluminum machining, this knowledge is even more important.

With increasing tool wear, two new areas with a high potential of increasing process stability are created (Fig. 19b). At spindle speeds of $\mathrm{n}=12,000 \mathrm{~min}^{-1}$ and $\mathrm{n}=20,000 \mathrm{~min}^{-1}$, the maximum depth of cut increases from $\mathrm{a}_{\mathrm{p}, \lim }=2 \mathrm{~mm}\left(\mathrm{n}=12,000 \mathrm{~min}^{-1}\right)$ and from $\mathrm{a}_{\mathrm{p}, \mathrm{lim}}=3 \mathrm{~mm}$ $\left(\mathrm{n}=20,000 \mathrm{~min}^{-1}\right)$ to $\mathrm{a}_{\mathrm{p}, \mathrm{lim}}=6 \mathrm{~mm}$ which corresponds to an increase of stability of $300 \%$ and $200 \%$ respectively. The areas b in Fig. 19 are the result of the calculation method and will be verified in future investigations.

The presented wear-stability map in milling Al7075 leads to the conclusion that stability peaks becoming higher by initial tool wear and other areas of the map show an increase of stability only with greater tool wear. With tool wear above a limit of $\mathrm{VB}=60 \mu \mathrm{m}$ a higher process stability in other areas can be observed. The knowledge of a wear-stability

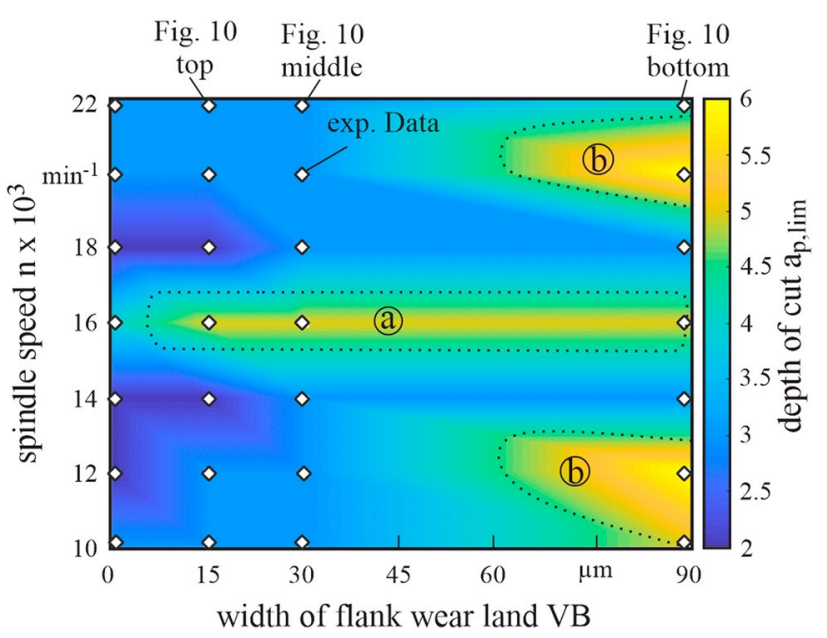

Fig. 19 Wear-stability map Al7075, tool: ratio mill alu RF 100 A, $\mathrm{f}_{\mathrm{z}}=0.1 \mathrm{~mm}, \mathrm{~d}=16 \mathrm{~mm}, \mathrm{z}=3$, slot milling map for a special milling process will help to fully exploit the potential of the machining setup.

\subsubsection{Milling of AISI 4140+QT with a long cantilevered indexable insert mill}

The wear-stability map for the machining process of AISI4140+QT is shown in Fig. 20. The highest depth of cut can be achieved with low spindle speeds of $n=1,300$ $\mathrm{min}^{-1}$ and width of flank wear from $\mathrm{VB}=30 \mu \mathrm{m}$ (Fig. 20a). Another area with high potential of increasing stability is at spindle speeds of $\mathrm{n}=5,500 \mathrm{~min}^{-1}$ and width of flank wear from $\mathrm{VB}=30 \mu \mathrm{m}$ (Fig. 20b).

The results confirm the investigations made in $[6,13]$. For high cutting speeds a high speed damping effect can be observed [13] and for low cutting speeds the effect of process damping is higher. The process damping here is also reinforced by the tool wear. With regard to an increased productivity the highest spindle speed of $n=5,500 \mathrm{~min}^{-1}$ will not be the optimum parameter due to the very high wear rate at these cutting speeds. The higher stability at low spindle speeds will lead to a longer tool life with also a high productivity. The presented wear-stability map is a useful method to determine the balance between tool life and high productivity.

\section{Conclusion and outlook}

In the contribution presented, the stability of milling processes with tools with defined width of flank wear was investigated. For this purpose, milling tests and simulations were carried out. Based on the results shown, the following conclusions can be drawn:

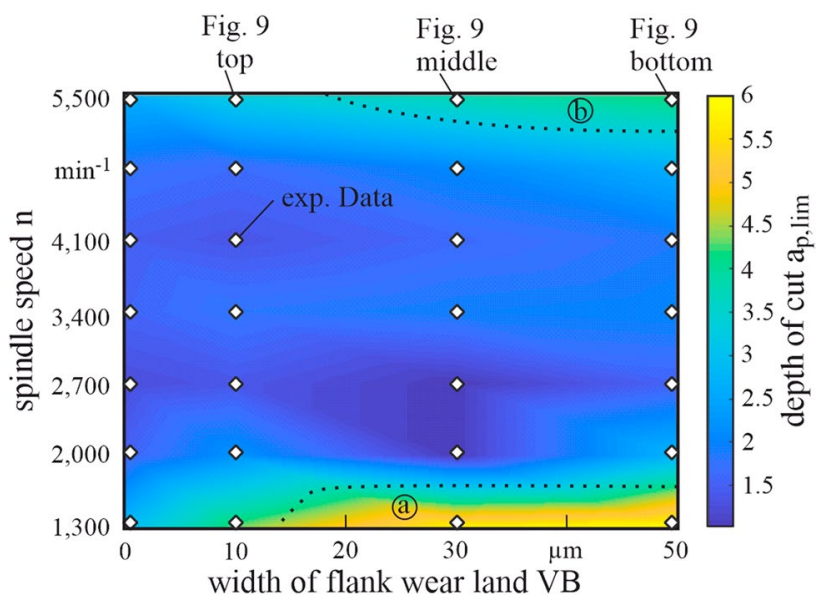

Fig. 20 Wear-stability map AISI 4140+QT, tool inserts: XOEX10T308R-M06, MM4500, $\mathrm{f}_{\mathrm{z}}=0.08 \mathrm{~mm}, \mathrm{~d}=20 \mathrm{~mm}, \mathrm{z}=2$, $\mathrm{a}_{\mathrm{e}}=2 \mathrm{~mm}$ 
- Higher process stability caused by process damping can be achieved with defined worn tools. The responsible mechanism is the larger contact area of the flank face and the workpiece, which leads to a damping force acting in the opposite direction of the tool oscillation.

- Even initial flank wear leads to a higher stability in certain areas of spindle speeds. This knowledge can be used to increase productivity in an early state of tool lifetime

- Stability peaks are reinforced by tool wear. With higher tool wear in milling aluminum new stability peaks emerge in different ranges of spindle speed.

- Wear stability maps can be used to visualize processes with a high potential to increase productivity due to process damping effects, which are the result of increased flank wear.

- A simulation based on the semi-discretization method was used to calculate the stability lobes of tools with defined wear in good agreement with experimental results.

- The results for milling aluminum Al7075 show that the stability can be increased for certain spindle speeds up to $300 \%$ compared to new sharp tools.

- Further improvements, e.g. an adapted process damping model, have to be realized, to increase the accuracy of the simulation. Another potential way of calculating stability charts is the use of time-domain milling simulations [16, 17].

Acknowledgements The presented investigations were undertaken with support of the German Federation of Industrial Research Associations $(\mathrm{AiF})$ within the project "Potential for increasing productivity through wear-related process damping" (IGF 20636 N/1). The authors would like to thank the AiF for the financial and organizational support of this project and the companies Seco Tools and Gühring KG for providing the milling tools.

Funding Open Access funding enabled and organized by Projekt DEAL.

Open Access This article is licensed under a Creative Commons Attribution 4.0 International License, which permits use, sharing, adaptation, distribution and reproduction in any medium or format, as long as you give appropriate credit to the original author(s) and the source, provide a link to the Creative Commons licence, and indicate if changes were made. The images or other third party material in this article are included in the article's Creative Commons licence, unless indicated otherwise in a credit line to the material. If material is not included in the article's Creative Commons licence and your intended use is not permitted by statutory regulation or exceeds the permitted use, you will need to obtain permission directly from the copyright holder. To view a copy of this licence, visit http://creativecommons.org/licenses/by/4.0/.

\section{References}

1. Munoa J, Beudaert X, Dombovari Z, Altintas Y, Budak E, Brecher C, Stepan G (2016) Chatter suppression techniques in metal cutting. CIRP Ann-Manuf Technol 65:785-808

2. Tlusty J, Polacek M (1957) Besipiele der behandlung der selbsterregten Schwingung der Werkzeugmaschinen. Hanser Verlag, Munich

3. Budak E, Altintas Y (1998) Analytical prediction of chatter stability in milling-part I: general formulation. J Dyn Syst Meas Contr 120(1):22-30

4. Stone B (2014) Chatter and machine tools. Springer, Switzerland

5. Denkena B, Biermann D (2014) Cutting edge geometries. CIRP Ann-Manuf Technol 63:631-653

6. Tunc L-T, Budak E (2012) Effect of cutting conditions \& tools geometry on process damping in machining. Int $\mathrm{J}$ Mach Tools Manuf 57:10-19

7. Wu DW (1988) Application of a comprehensive dynamic cutting force model to orthogonal wave-generating processes. Int J Mech Sci 30(8):581-600

8. Denkena B, Bickel W, Sellmeier V (2012) Flank milling of compliant workpieces with chamfered tools. Prod Eng: Res Dev 6:403-412

9. Klocke F (2018) Fertigungsverfahren 1-Zerspanung mit geometrisch bestimmter Schneide, 9th edn. Springer, Berlin

10. Ahmadi K, Ismail F (2012) Stability lobes in milling including process damping and utilizing multi-frequency and semi-Discretization methods. Int J Mach Tools Manuf 54-55:45-54

11. Altintas Y, Eynian M, Onozuka H (2008) Identification of dynamic cutting force coefficients and chatter stability with process damping. CIRP Ann-Manuf Technol 57(1):371-374

12. Tyler CT, Schmitz TL (2013) Analytical process damping stability prediction. J Manuf Process 15(1):69-76

13. Denkena B, Sellmeier V (2012) High speed process damping in milling. CIRP J Manuf Sci Technol 5(1):8-19

14. Grabowski R (2019) Enhanced simulation of the milling process for a novel roughing and finishing tool. PhD-Thesis, Leibniz Universität Hannover. https://doi.org/10.15488/9944

15. Gradisek J, Kalveram M, Weinert K (2004) Mechanistic identification of specific force coefficients for a general end mill. Int $\mathrm{J}$ Mach Tools Manuf 44:401-414

16. Denkena B, Pape O, Grove T, Mücke A (2019) Advanced process design for re-contouring using a time-domain dynamic material removal simulation. 12th CIRP conference on intelligent computation in manufacturing engineering. Procedia CIRP 79:21-26

17. Wöste F, Baumann J, Wiederkehr P, Surmann T (2019) Analysis and simulation of process damping in HPC milling. Prod Engs $13: 607-616$

Publisher's Note Springer Nature remains neutral with regard to jurisdictional claims in published maps and institutional affiliations. 